\title{
Cytotaxonomy of Ficoideae
}

\author{
Arun Kumar Sharma and Sibdas Ghosh \\ Cytogenetics Laboratory, Department of Botany, University of Calcutta, \\ 35 Ballygunge Circular Road, Calcutta-19, India
}

Received November 14, $196 \%$

\section{Introduction}

The order Ficoideae of Bentham and Hooker (1883) included three different tribes, Mesembryeae, Aizoideae, and Mollugineae. Within Mesembryeae, Mesembryanthemum and Tetragonia were included whereas Aizoon, Caleria, Plinthus, Acrosanthus, Gunnia, Sesuvium, Trianthema, Sypselia, were included within the tribe Aizoideae. Mollugineae contained the different genera Mollugo, Oryzia, Macarthesia, Telephium, Coclanthus, Psammatrophia, Palpoda, Adenogramma, Gisekia, Semonvillea and Limeum. On the other hand Rendle (1938) subdivided Aizoaceae into two sub-families Molluginoideae and Ficoideae. The subfamily Molluginoideae consisted of Mollugo and Gisekia while the subfamily Ficoideae, was again subdivided into three tribes, Sesuvieae, containing Sesuvium and Trianthema, Aizoeae with Aizoon and Mesembryanthemae, including the genera Mesembryanthemum and Tetragonia. Lastly Hutchinson (1959) in his system of classification established two separate families Molluginaceae and Ficoidaceae. The occurrence of these discrepancies with regard to the systematic status of the genera included within these two families calls for a thorough cytotaxonomic study.

Moreover, the cytological studies, carried out so far, have revealed some interesting data. Within Molluginaceae, both in Mollugo and Gisekia, a basic chromosome number of $n=9$ has been reported. In Ficoidaceae on the other hand $\mathrm{n}=9$ is on record in the semi-succulent group and $\mathrm{n}=9$ in the succulent one. Recently Sharma and Bhattacharyya (1956) have also studied a number of genera of this family; in which the importance of polyploidy and structural alteration of chromosomes in speciation have been pointed out.

In view of the interesting cytological observations noted in some of the genera studied and also of the scope of the detailed cytotaxonomic study, the present work was undertaken.

\section{Materials and methods}

The fifteen species belonging to eleven genera formed the source of materials. Mollugo spergula is a non-succulent plant with terrestrial habit

1 This research has been financed in part by a grant made by the United States Department of Agriculture under PL 480 (FG-IN-222). 
and superior ovary, whereas Trianthema monogyna has thick leaves, and is a semi-succulent with superior ovary. Both are common weeds of West Bengal. The other plants are horticultural succulents with inferior ovary. They were obtained from the Imperial Nursery in Calcutta, the Ghosh Nursery at Darjeeling and the Chandra Nursery at Kalimpong.

Studies of the somatic chromosomes were mainly made from temporary squash preparations of young healthy root tips. Different pretreating chemicals were tried of which $0.002 \mathrm{M}$ aq. oxyquinolene solution for ten to fifteen minutes at $4^{\circ} \mathrm{C}$ and two hours forty five to fifty minutes at $8^{\circ}-10^{\circ} \mathrm{C}$ was found to be most suitable. The root-tips were fixed in acetic-alcohol $(1: 2)$ mixture for one hour, followed by heating for a few seconds and staining in $2 \%$ aceto-orcein solution and $\mathrm{N}$. $\mathrm{HCl}$ mixture $(9: 1)$. The root tips were kept overnight in the stain and finally squashed in $45 \%$ acetic acid. The squashes were made permanent by inverting the slides in tertiary butyl alcohol till the cover slip detached and then mounting in euparal.

Figures were drawn with $\times 12.5$ eye piece and on 1.3 apochromatic objective with a condenser of 1.3 N.A. at a table magnification of approximately $\times 1950$.

In the figures and idiograms, the chromosomes with secondary constrictions have been drawn in outline.

\section{Observations}

The observations show that the species investigated form a natural assemblage. Except only two species namely Trianthema monogyna with $2 \mathrm{n}=28$ and Bergeranthus jamesii $2 \mathrm{n}=66$, all the other species have $2 \mathrm{n}=18$ chromosomes or multiples of 9 . In general, they range from medium sized to short with a definite gradation in size. The individual karyotypes can be described as follows:-

1. Mollugo spergula Linn. $\left(2 \mathrm{n}=36=\mathrm{A}_{4}+\mathrm{A}_{2}{ }^{\prime}+\mathrm{B}_{2}+\mathrm{C}_{20}+\mathrm{D}_{8}\right)$

The somatic complement of this species contains $2 n=36$ chromosomes (Fig. 1), three pairs of chromosomes bear secondary constrictions.

The morphology of the chromosomes, on the basis of their length and positions of the constrictions, may be described as follows:

Type A :-Two pairs of comparatively long chromosomes $(5.12 \mu$ and $4.48 \mu)$, each with two constrictions, primary and secondary, one nearly median and the other nearly submedian on the comparatively shorter distal arm.

Type $\mathrm{A}^{\prime}$ :- One pair of comparatively long chromosomes $(4.16 \mu)$, each with a nearly median primary constriction and satellite at the distal end of the shorter arm.

Type B :- One pair of comparatively long chromosomes $(4.16 \mu)$, having nearly median primary constrictions. 
Type C:-Ten pairs of medium sized chromosomes, $(3.84 \mu$ to $2.56 \mu)$, having median to nearly submedian primary constrictions.

Type D:-Four pairs of short chromosomes (1.92 $)$, having median to nearly median primary constrictions.

In meiosis eighteen bivalents have been noted in metaphase I

(Fig. 2) and eighteen chromosomes in the first pollen division (Fig. 3).

2. Trianthema monogyna Linn. $\left(2 \mathrm{n}=28=\mathrm{A}_{2}+\mathrm{B}_{2}\right.$ $\left.+\mathrm{C}_{10}+\mathrm{D}_{14}\right)$

The somatic complement of the species contains $2 \mathrm{n}=28$ chromosomes (Fig. 4), varying in length from $3.20 \mu$ to $1.92 \mu$. One pair of chromosomes with two constrictions was noticed

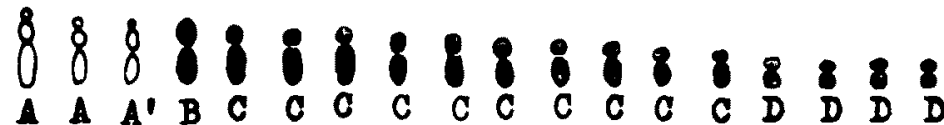

$A$ A A' B C C C C C C C C C C
Mollugo spergula

1

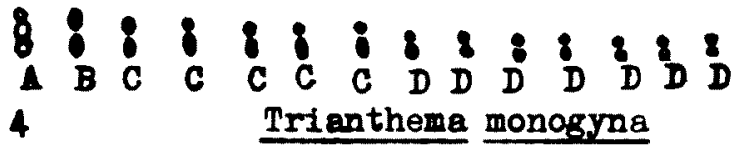

88 รे

$\triangle A A B$ B B
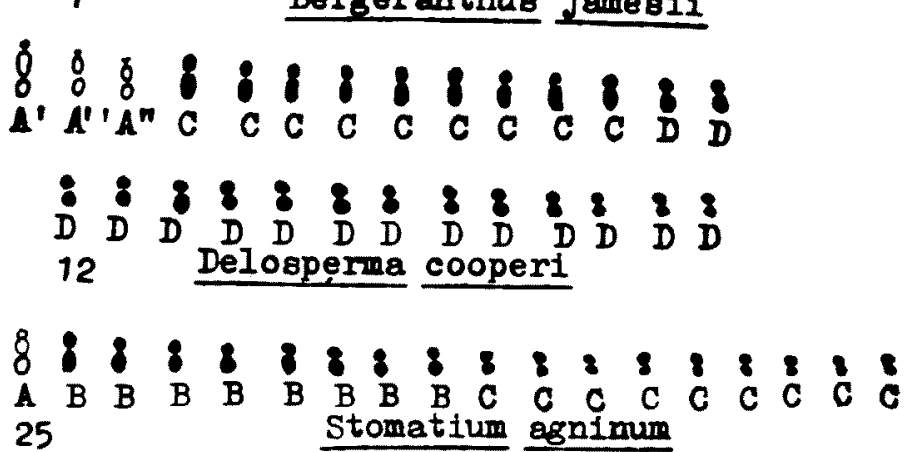

Figs. 1, 4, 7, 12, 25. Explanations in the text. (Fig. 4).

Type A :-One pair of comparatively long chromosomes $(3.20 \mu)$, each with two constrictions, primary and secondary, at nearly submedian positions at opposite ends; both the end and median segments are equal in length, whereas the distal arm is shorter.

Type B:-One pair of comparatively long chromosomes $(3.20 \mu)$, with median primary constrictions.

Type C:-Five pairs of medium sized chromosomes (2.88 $\mu$ to $2.24 \mu$ ), with submedian to nearly median primary constrictions.

Type D:- Seven pairs of short chromosomes $(1.92 \mu)$, with nearly median to median primary constrictions.

In meiosis fourteen bivalents were observed in metaphase I (Fig. 5).

3. Argyroderma jacobsonianum Schwantes $\left(2 \mathrm{n}=18=\mathrm{A}_{2}+\mathrm{A}_{2}^{\prime}+\mathrm{B}_{2}+\mathrm{C}_{8}\right.$ $\left.\mathrm{D}_{4}\right)$. 

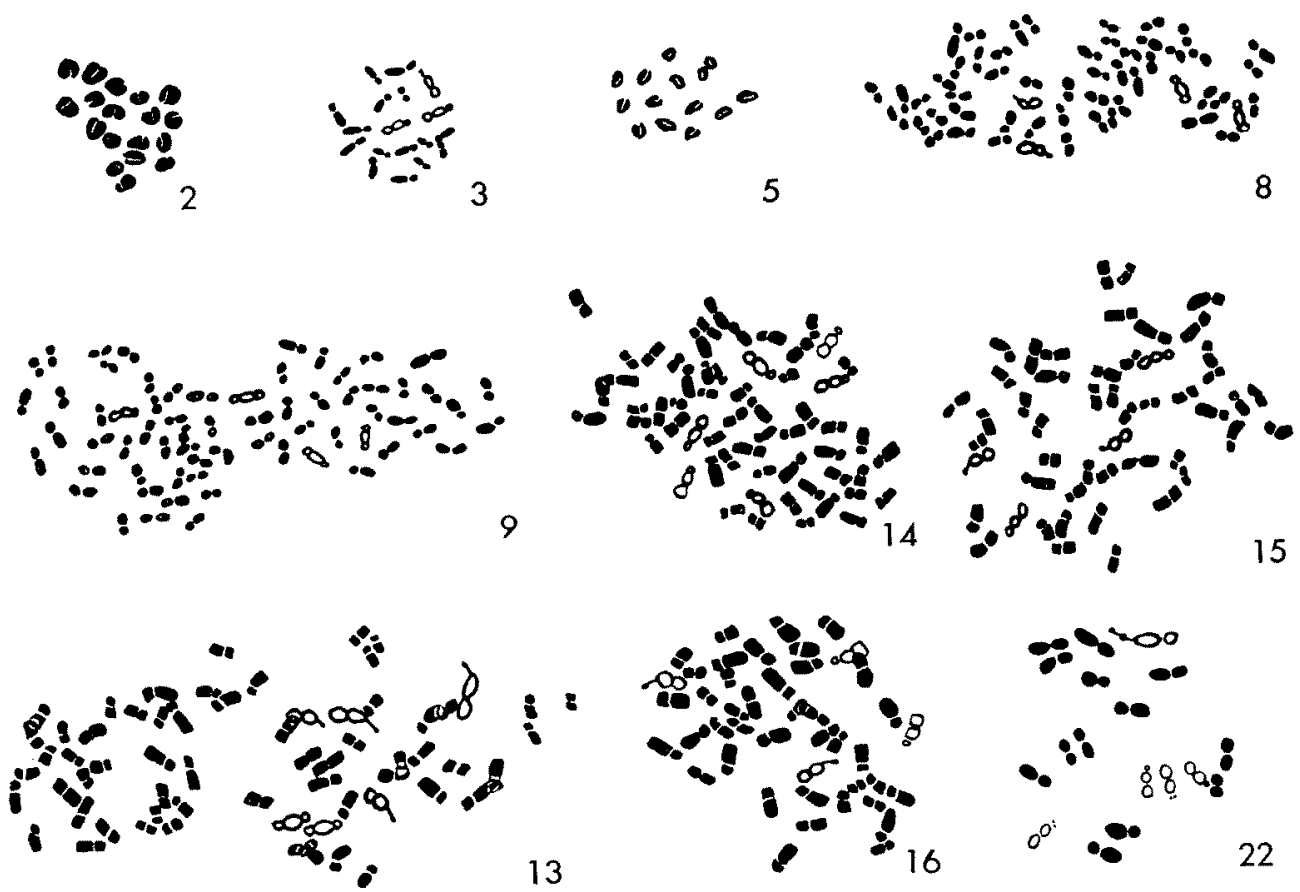

Figs. 2, 3, 5, 8, 9, 13, 14, 15, 16, 22. Explanations in the text.

Somatic com-

$\begin{array}{lllllllll}8 & 8 & 1 & 1 & : & 1 & 1 & : & 1 \\ 8 & 0 & 1 & c & 1 & c & 0 & 0 & 0\end{array}$

10 Chetridopsis ransylit

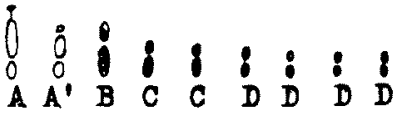

Delosperma eohinatum

11

$\begin{array}{lllllllll}8 & 8 & 8 & 8 & 8 & 8 & : & : & 8 \\ 8 & B & C & C & D & D & D & D & E\end{array}$

17 Faucaria tigrina

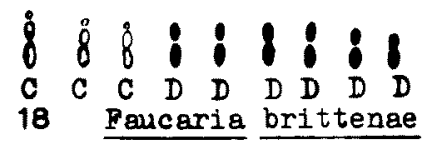

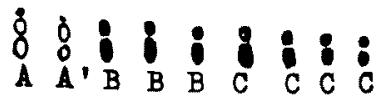

$\frac{\text { Glott1phyllum depressum }}{21}$

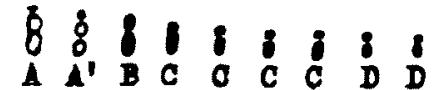
Argyroderma jacobsoniamm 6

$\begin{array}{llllllllll}8 & 8 & 8 & 8 & 8 & 8 & : & 8 & 8 \\ C & C & C & D & D & D & 8 & 2 & 8\end{array}$ Faucaria acutipetala 19

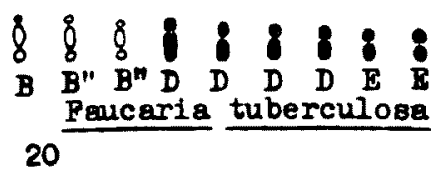

$819: 911:$

23 Lithops fulvioeps

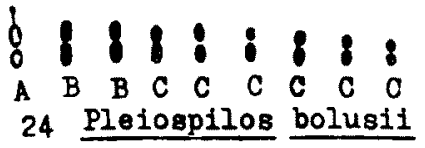

Figs. $6,10,11,17,18,19,20,21,23,24$. Explanations in the text.

plements show $2 \mathrm{n}=18$ chromosomes (Fig. 6), from $3.52 \mu$ to $1.60 \mu$ long. Two pairs of chromosomes bear secondary constrictions (Fig. 6a).

Type A :-A pair of comparatively long chromosomes $(3.52 \mu)$, each with a nearly median primary constriction and a satellite at the distal end of one arm. 
Type $\mathrm{A}^{\prime}$ : - A pair of comparatively long chromosomes $(3.20 \mu)$, each with two constrictions, primary and secondary. One constriction is nearly median in position and the other nearly subterminal at the distal end of the longer arm.

Type B :-A pair of relatively long chromosomes (3.20 $\mu$ ), with nearly submedian primary constrictions.

Type C :-Four pairs of medium sized chromosomes $(2.56 \mu$ to $1.92 \mu)$, having nearly median primary constrictions.

Type D :-Two pairs of short chromosomes (1.6(1) , with median constrictions.

4. Bergeranthus jamesii $\mathrm{L}$. Bolus $\left(2 \mathrm{n}=66=\mathrm{A}_{4}+\mathrm{A}_{2}^{\prime}+\mathrm{B}_{8}+\mathrm{C}_{52}\right)$

Somatic complements show $2 \mathrm{n}=66$ chromosomes (Fig. 7). Variation numbers like $2 n=54$ and $2 n=62$ were also obtained (Figs. 8 and 9) in the somatic cells.

Type A :-Two pairs of medium sized chromosomes longest in the set, each with two constrictions, primary and secondary. One constriction is nearly median and the other nearly subterminal at the distal end of the slightly larger arm, $(3.20 \mu$ and $2.56 \mu)$.

Type $A^{\prime}$ :-One pair of medium sized chromosomes $(2.56 \mu)$, each with a nearly median primary constriction and a satellite at the distal end of the slightly longer arm.

Type B :-Four pairs of medium sized chromosomes $(2.56 \mu)$, with nearly median primary constrictions.

Type C :-Twenty six pairs of chromosomes $(1.92 \mu$ to $1.28 \mu)$, having median primary constrictions.

5. Cheiridopsis vanzylii $\mathrm{L}$. Bolus $\left(2 \mathrm{n}=18=\mathrm{A}_{4}+\mathrm{B}_{2}+\mathrm{C}_{8}+\mathrm{D}_{4}\right)$

$2 \mathrm{n}=18$ chromosomes are present in the somatic cells (Fig. 10). Two pairs of chromosome bear secondary constrictions.

Type A :-Two pairs of relatively long chromosomes $(4.08 \mu)$, each with two constrictions, primary and secondary, one constriction nearly median and the other subterminal at the distal end of the longer arm.

Type B :- One pair of relatively long chromosomes having nearly median primary constrictions $(4.16 \mu)$.

Type C :-Four pairs of medium sized chromosomes (3.52 $\mu$ to $2.88 \mu$ ), with nearly median primary constrictions.

Type D:-Two pairs of short chromosomes $(2.56 \mu)$, with median primary constrictions.

6. Delosperma N. E. Brown

Two species under this genus were worked out. The chromosomes show 
a general resemblance in size and positions of primary and secondary constrictions. The following general types are present:

Type A :-Long chromosome with a submedian primary constriction and a satellite at the distal end of the long arm. The gap is bridged by a satellite thread.

Type $\mathrm{A}^{\prime}$ : - Relatively long chromosome with two constrictions, primary and secondary, one nearly submedian in position and the other nearly subterminal at the distal end of the long arm.

Type $A^{\prime \prime}$ :- Medium sized chromosome with a nearly median primary constriction and a satellite with satellite thread at the distal end of one arm.

Type B :-Medium sized chromosome with nearly submedian primary constriction.

Type $\mathrm{C}:-$ Medium sized chromosome with nearly submedian primary constriction.

Type D :- Short chromosome with median primary constriction.

I. Delosperma echinatum Schwantes $\left(2 \mathrm{n}=18=\mathrm{A}_{2}+\mathrm{A}_{2}^{\prime}+\mathrm{B}_{2}+\mathrm{C}_{4}+\mathrm{D}_{8}\right.$ $=5.4 \mu-1.9 \mu)$ (Fig. 11).

II. D. cooperi L. Bolus $\left(2 \mathrm{n}=54=\mathrm{A}_{2}^{\prime}+\mathrm{A}_{4}^{\prime \prime}+\mathrm{C}_{18}+\mathrm{D}_{30}=3.8 \mu-1.6 \mu\right)$ (Fig. 12).

Somatic cells with variable chromosome numbers like $2 \mathrm{n}=64$ (Fig. 13), $2 \mathrm{n}=60$ (Fig. 14), $2 \mathrm{n}=50$ (Fig. 15) and $2 \mathrm{n}=44$ (Fig. 16) were also observed.

\section{Faucaria Schwantes}

Four species were worked out under this genus. They show a general resemblance in chromosome size and morphology except $F$. tigrina which has a pair of chromosomes with supernumerary constrictions. The chromosomes vary in size from nearly long to very short, forming a graded series. The types seen are:

Type A:-Long chromosome with three constrictions. One constriction is nearly subterminal and another nearly submedian at the distal end of the longer arm. A satellite is located at the distal end of the short arm after the submedian constriction.

Type B:-Medium sized chromosome with two constrictions, primary and secondary, one nearly submedian and the other nearly subterminal at opposite ends of the chromosome.

Type B':- Medium sized chromosome with two constrictions. They are like the $\mathrm{B}$ type but have the distal arms equal in size.

Type C:-Medium sized chromosome with two constrictions, primary and secondary, one nearly median and the other nearly subterminal at the distal end of the one arm.

Type $\mathrm{C}^{\prime}$ :-Medium sized chromosome like $\mathrm{C}$ type in which the small distal segment is a satellite.

Type D :-Medium to short sized chromosome with nearly median to 
median primary constriction.

Type E:-Very short chromosome with median primary constriction.

I. F. tigrina Schwantes $\left(2 \mathrm{n}=18=\mathrm{A}_{2}+\mathrm{B}_{2}+\mathrm{C}_{2}+\mathrm{C}_{2}^{\prime}+\mathrm{D}_{8}+\mathrm{E}_{2}=4.8 \mu\right.$ to $2.2 \mu)$ (Fig. 17).

II. F. brittenae L. Bolus $\left(2 \mathrm{n}=18=\mathrm{C}_{6}+\mathrm{D}_{12}=4.4 \mu\right.$ to $\left.2.8 \mu\right)$ (Fig. 18).

III. F. acutipetala L. Bolus $\left(2 \mathrm{n}=18=\mathrm{C}_{4}+\mathrm{C}_{2}+\mathrm{D}_{6}+\mathrm{E}_{8}=4.1 \mu\right.$ to $\left.1.9 \mu\right)$ (Fig. 19).

IV. F. tuberculosa Schwantes $\left(2 \mathrm{n}=18=\mathrm{B}_{2}+\mathrm{B}_{4}^{\prime}+\mathrm{D}_{8}+\mathrm{E}_{4}=3.5 \mu\right.$ to $\left.2.5 \mu\right)$ (Fig. 20).

8. Glottiphyllum depressum N. E. Brown $\left(2 \mathrm{n}=18=\mathrm{A}_{2}+\mathrm{A}_{2}^{\prime}+\mathrm{B}_{8}+\mathrm{C}_{6}\right)$

The somatic complements show $2 \mathrm{n}=18$ chromosomes (Fig. 21). In some plates one chromosome with supernumerary constrictions was found (Fig. 22). The chromosomes, in general, are of four types.

Type A:-One pair of chromosomes $(4.16 \mu)$, with two constrictions primary and secondary, one nearly median and the other nearly subterminal at the distal end of one arm.

Type $\mathrm{A}^{\prime}$ :- One pair of chromosomes $(3.84 \mu)$, similar to A type but the median segment is slightly longer than the end segment.

Type B :-Four pairs of medium sized chromosome $(3.52 \mu$ to $3.20 \mu)$, with nearly median primary constrictions.

Type C:- Three pairs of short chromosomes $(2.56 \mu)$, with median primary constrictions.

9. Lithops fulviceps N. E. Brown $\left(2 \mathrm{n}=18=\mathrm{A}_{2}+\mathrm{B}_{2}+\mathrm{C}_{10}+\mathrm{D}_{4}\right)$

In the somatic cells eighteen chromosomes are found (Fig. 23). They are of four types.

Type A :-One pair of comparatively long chromosomes $(4.80 \mu)$, each with two constrictions, primary and secondary. The two constrictions are located in nearly median positions very close to each other.

Type B :-One pair of relatively long chromosomes $(4.48 \mu)$ with median primary constrictions.

Type C:-Five pairs of medium sized chromosomes (4.48 $\mu$ to $3.84 \mu)$, with nearly median primary constrictions.

Type D:-Two pairs of short chromosomes $(3.20 \mu$ to $2.88 \mu)$, with median primary constrictions.

10. Pleiospilos bolusii N. E. Brown $\left(2 \mathrm{n}=18=\mathrm{A}_{3}+\mathrm{B}_{4}+\mathrm{C}_{12}\right)$

The somatic cells show $2 n=18$ chromosomes in their nuclei (Fig. 24). They are, in general, of three types (Fig. 24a).

Type A:-One pair of comparatively long chromosomes $(4.80 \mu)$, each with a nearly median primary constriction and a satellite with a long satellite stalk at the distal end of one arm. The middle 
segment is slightly larger than the end segments.

Type B:-Two pairs of medium sized chromosomes $(3.20 \mu)$, with median primary constrictions.

Type C:-Six pairs of short chromosomes $(2.88 \mu$ to $1.92 \mu)$, with nearly median to median primary constrictions.

11. Stomatium agninum Schwantes $\left(2 \mathrm{n}=36=\mathrm{A}_{2}+\mathrm{B}_{16}+\mathrm{C}_{18}\right)$

Somatic cells show $2 n=36$ chromosomes (Fig. 25).

Type A :-A pair of comparatively long chromosomes, each with two constrictions, primary and secondary, one nearly median and the other nearly subterminal at the distal end of the long arm. The basal and middle arms of the chromosomes are almost equal in length, whereas the distal arm is much shorter.

Type B :- Eight pairs of chromosomes ranging from medium sized to short $(2.88 \mu$ to $1.92 \mu)$. The chromosomes bear nearly submedian primary constrictions.

Type C :-Nine pairs of short chromosomes $(1.60 \mu$ to $1.28 \mu)$, with median primary constrictions.

\section{Discussion}

\section{Chromosome counts and polyploidy}

Inspite of the fact that a considerable amount of study of chromosome counts in different genera of the families Ficoidaceae and Molluginaceae has been carried out, very little work on the karyotype analysis with improved methods was done earlier. In the present work, in addition to the study of cytological behaviour of the species investigated, emphasis has been laid on an analysis of detailed morphology of chromosomes, in view of the scope of structural alterations in speciation, as pointed out by previous workers (Sharma and Bhattacharyya 1956). Consequently in addition to an attempt towards solving the problem of taxonomic dispute in these families, efforts have been focussed to assess the importance of chromosomal alterations in their speciation.

For a long time, till the publication of N. E. Brown, Schwantes, and Bolus' works (Vide Index Kewensis, Supplementum vii ; 18, 47, 137, 190 ; Supplementum vii: 29, 94, 230, 245 etc.), Mesembryanthemum was considered to be a single genus, which along with Tetragonia, was included within Mesembryanthemeae of the subfamily Ficoideae of Rendle (1938), within the tribe Mesembryeae of the order Ficoideae of Bentham and Hooker. Brown, Schwantes and others divided Mesembryanthemum into a large number of genera all of which are no doubt characterised by their succulent nature.

In all genera, created by subdividing Mesembryanthemum, a constant chromosome number of 9 in the basic set has been observed. They represent either diploid or polyploid levels. In the present investigation $2 \mathrm{n}=18$ chro- 
mosomes have been found in Faucaria tigrina, F. brittenue, $F$. acutipetala, F. tuberculosa, Lithops fulviceps, Cheiridopsis vanzylii, Argyroderma jacobsonianum, Delospermaechinatum, Glottiphyllum depressum and Pleiospilos bolusii, $2 \mathrm{n}=36$ in Stomatium agninum, and $2 \mathrm{n}=54$ in Lelosperma cooperi $(2 n=72$ in Sugiura 1944), thus proving that the basic number of 9 chromosomes is deep seated for this group of genera. $2 n=66$ chromosomes have been observed in only one species, namely Bergeranthus jamesii. The four other species of Bergeranthus reported previously contained either 18, 27 or 36 chromosomes. It is difficult to state the origin of 66 chromosomes in this species of this genus. It may be either a derivation from a heptaploid species or more likely a species hybrid with $2 n=63$ chromosomes through the addition of certain chromosomes in the set, or a derivation through loss of a few chromosomes from an octaploid $(2 n=72)$. In any case the present investigation shows the existence of aneuploid chromosome numbers in this genus, which is rather unusual for this plant. In Bergeranthus scapiger incidentally interspecific polyploidy has been recorded (Snoad 1951). The role of polyploidy and aneuploidy in the speciation of this genus can easily be guessed from the perusal of previous and present records. Out of the different genera created from subdividing Mesembryanthemum, two separate sections have been established so far, one including purely diploid genera and the other including polyploids as well (vide Darlington and Wylie 1955). The genus Stomatium according to this grouping has been placed under the first section, as four species so far studied all contain $2 \mathrm{n}=18$ chromosomes (de Vos 1947, Snoad 1951). In the present work, on the other hand, in another species of Stomatium, S. agninum, a high chromosome number of $2 \mathrm{n}=36$ has been recorded suggesting that within this genus also polyploidy is prevalent. It should therefore, be transferred to the second section which includes polyploids as well.

With regard to the chromosome numbers of the genera included under semi-succulents, Trianthema presents certain data requiring special comment. In it, diploid, polyploid and aneuploid chromosome numbers have been reported in different species. $T$. decandra, $T$. pentandra, $T$. polysperma have $2 \mathrm{n}=16$ chromosomes (Hagerup 1952, Raghavan and Srinivasan 1940). 2n=32 chromosomes have been observed in $T$. cristallina indicating the presence of polyploidy (Hagerup 1932). However, the figure presented by Hagerup of the chromosome behaviour in his material of $T$. cristallina, does not bear absolute evidence of 32 as the chromosome number. It shows 7 bivalent like configurations during meiosis which Hagerup interpreted as 7 quadrivalents or rather 14 bivalents, each of which represents an association of 2 bivalents. In that case also the chromosome number comes to be 28 instead of 32 . Moreover none of these assumptions are clearly borne out from the figures which show evidence of clumping. On the basis of this fact it becomes difficult to assume the existence of interspecific aneuploids in $T$. cristallina. 
T. monogyna on the other hand, had shown a chromosome number of $2 \mathrm{n}=26$ in individuals studied by Raghavan and Srinivasan (1940) as well as by Sharma and Bhattacharyya (1956). A different population of $T$. monogyna studied during the present investigation indicates the presence of $2 \mathrm{n}=28 \mathrm{chro}$ mosomes in root-tip cells and 14 clear bivalents during meiosis, indicating the incidence of interspecific aneuploidy in this taxon. Apparently phenotypic differences between individuals studied by Sharma and Bhattacharyya and the present author could not be detected. Possibly a thorough scrutiny may reveal minute morphological differences which will have to be worked out later.

The incidence of $2 \mathrm{n}=26$ and $2 \mathrm{n}=28$ chromosomes in T. monogyna, also emphasizes the role of aneuploidy in speciation of Trianthema. Apparently, in the semisucculent genera, numerical chromosome variations are quite common as compared to the constancy in the basic set noted in the succulents.

In Sesuvium portulacastrum, Raghavan and Srinivasan (1940) noted $2 \mathrm{n}=48$ chromosomes, whereas Sugiura (1936) observed $2 \mathrm{n}=32$ chromosomes. Sugiura, however, identified his material as Aizoon canariense, which in fact was Sesuvium portulacastrum (vide Darlington and Wylie 1955). Apparently, the basic set here is $\mathrm{n}=8$, and 32 and 48 chromosomes recorded by different authors suggest different degrees of polyploidy. The occurrence of the basic set as $n=8$ rather than $n=16$ is borne out from the chromosome numbers reported in the allied genera. Sharma and Bhattacharyya (1956), however, recorded $2 n=36$ chromosomes in this very species, indicating once more the incidence of intraspecific polyploidy and aneuploidy in this genus. $2 n=36$ chromosomes indicating a basic number of 9 , is evidently a derivation from a basic set of 8 , representing $2 \mathrm{n}=32$ chromosomes. A thorough search probably may reveal even diploids with $2 n=16$ and 18 chromosomes in this species. The scope of such a possibility is indicated by the wide range in phenotypic appearance noted in the different populations of $S$. portulacastrum.

\section{Cytoecological considerations}

The chromosome numbers, taken in conjunction with the habit and habitat of the species, present an interesting possibility. Though all the individuals included within $S$. portulacastrum are regarded as seaside purselanes, the conditions under which they grow vary widely; some of them grow near the sea side in physiological dry soil, some near the completely dry sandy areas, whereas others even in fresh water pockets near sea side. The chromosome number with the basic sets of 8 and 9 may be correlated with these features. Moreover even though considered to be a semisucculent, certain individuals of $S$. portulacastrum show extremely succulent morphological characters. Such individuals may contain $n=9$ chromosomes which may represent the progenitor of Mesembryanthemum and the genera created by its subdivisions, which are pure succulents with $n=9$ chromosomes.

However, one disadvantage of considering Sesuvium as the progenitor 
of succulents may lie in the possible argument that this wide variability in the habitat of $S$. portulacastrum may be due to its polyploid constitution, which naturally confers an adaptive advantage on the taxon (Löve and Löve 1949). But inspite of the scope of such polyploids both polyploids and aneuploids have been found in $S$. portulacastrum. In view of this wide variability of chromosome number, it is quite expected that diploids too may be revealed from any population through closer scrutiny.

In Mollugo forms starting from diploids upto hexaploids are recorded (Sugiura 1936, Raghavan and Srinivasan 1940, Sharma and Bhattacharyya 1956), including interspecific polyploidy in M. pentaphylla (Sugiura 1936). In $M$. spergula, studied by the present authors, a tetraploid chromosome number of $2 \mathrm{n}=36$ has been recorded. In M. verticillata an aneuploid chromosome number of $2 n=64$ has been reported by Sugiura (1936). It is evident, therefore, that in this genus principally polyploidy and to some extent aneuploidy are responsible for speciation. Inspite of the incidence of polyploidy this genus has a constant preference for slightly marshy to terrestrial areas in the tropical regions. No variability in the habitat has so far been observed. Later investigations may reveal differences in imperceptible physiological preferences in different populations.

Karyotype analysis and systematic status of different taxa

Karyotype analysis with the aid of improved technique has been carried out in all species investigated during the present investigation. The details of chromosome morphology have brought out differences between different species, in the sense that no taxon has been found to be exactly identical in its karyotype with the other taxon. Evidently the role of structural alterations of the chromosomes in the evolution at both specific and generic levels is quite apparent, as also seen by the presence of supernumerary constrictions in $F$. tigrina since such supernumerary constrictions can originate through continued translocations involving the constriction regions of different chromosomes.

Inspite of the minute differences in the karyotypes of different taxa, a remarkable factor is that broadly all the species investigated so far have a gross resemblance in their karyotypes. The differences between the karyotypes principally involve the nature, number and position of the secondary constrictions in the complements. Such a gross resemblance in the karyotype of different genera, evidently indicates the homogeneity of all the genera included under Ficoideae of Bentham and Hooker, as well as Molluginaceae and Ficoidaceae of later authors. This homogeneity is also evidenced by the total amount of chromatin matter in proportion to chromosome numbers in different taxa (vide Histogram Fig. 26). Further evidences of their affinities are exemplified in chromosome numbers which show a basic set of 8 or 9 . That either of these two numbers has been derived from the other is indicated by genera like Sesuvium, where intraspecific variations involving the 
multiples of both these numbers are present.

In view of all the above facts, it seems reasonable to assume that the inclusion of different genera in three tribes under one family Ficoideae is justified. However, the term Ficoideae should naturally be replaced by Ficoidaceae.

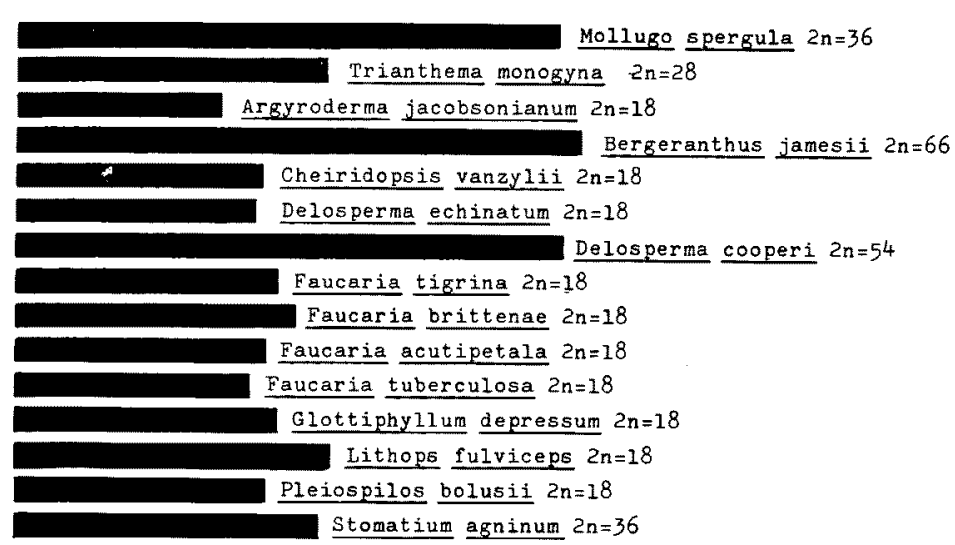

Fig. 26. Histogram. No cytological evidences have so far been brought forward to justify the creation of two families Molluginaceae and Ficoidaceae.

If the status of Ficoideae, embracing all these genera, is regarded as accepted, then the relative primitiveness of the three tribes need also to ascertained. The cytological evidences so far gathered suggest the primitiveness of Aizoideae. This includes, in addition to others, the genera Trianthema and Sesuvium. The habits of the species of Trianthema vary from nearly herbaceous to semisucculents, whereas that of Sesurium goes even upto the succulent type. On the basis of the wide preference of habitat in $S$. portulacastrum, including the different types of chromosome numbers noted in them, it may be suggested that two evolutionary lines have emerged from Sesuvium-like ancestors. One of them led towards terrestrial forms culminating in Mollugo and related genera included under Mollugineae of Bentham and Hooker and Molluginaceae of Hutchinson. The other line led to pure succulents represented by Mesembryeae of Bentham and Hooker, including Mesembryanthemum and the genera created out of its subdivision. In both these lines the chromosome number 9 is predominant. The chromosome number 8 as noted in Trianthema, Tetragonia and others, seems to be a derivation adapted to certain conditions of environment. More evidences on these lines of evolution starting from Sesuvium like ancestor must await thorough investigations on other genera of Ficoideae.

On the basis of cytological evidences nothing definite can be said at present of the relationship of Molluginaceae and Caryophyllaceae as suggested by Hutchinson (1959).

\section{Variation in karyotype and its significance}

In Bergeranthus jamesii and Delosperma cooperi in the somatic tissue, nuclei have been observed with chromosome numbers other than the one representing the regular $2 \mathrm{n}$ complement. Such alterations are found to be of widespread occurrence in species reproducing through vegetative means, where 
they have shown a significant role in speciation through their participation in the formation of daughter cells (Sharma 1956). In the genera investigated here too, their importance cannot at all be ignored, in view of the extensive vegetative propagation in these taxa, in addition to the sexual method of propagation. Investigation in these directions concerning the relative importance of sexual and vegetative means of speciation in this family may lead to interesting results.

\section{Summary}

Cytological investigations on 15 species of Ficoideae of Bentham and Hooker have been worked out with the aid of improved methods. A homogeneity in chromosome number and structure in all the genera has been found. The acceptance of the status of Ficoideae (or Ficoidaceae) embracing all these genera under three tribes as created by Bentham and Hooker has been stressed. The tribe Aizoideae having a basic set of 8 or 9 and with a wide range of habit and habitat is the most primitive among these three tribes. Two separate evolutionary lines emerged from the Sesurium-like ancestral stock, one led to the terrestrial forms of the tribe Mollugineae and the other to pure succulents of the tribe Mesembryeae. Both the above tribes have predominantly a basic set of 9 . The genera like Trianthema, Tetragonia with a basic set of 8 chromosomes seem to be derivations adapted to certain conditions of environment.

Lastly, the occurrence of variation in chromosome numbers in two species has been discussed and the need of investigations in this direction concerning the relative importance of sexual and vegetative means of speciation in this family has been stressed.

\section{References}

Bentham, G. and Hooker, J. D. 1883. Genera Plantarum, 1: London.

*Bolus, L. 1927. Fl. Pl. S. Afr. 7: 259-262.

*- 1927. S. Afr. Gard. 17: 281-327.

*-1928. S. Afr. Gard. 18: 279.

Brown, N. E. 1928. New and old species of Mesembryanthemum, with critical notes. J. Linn. Soc. Bot. 45: 53.

* - 1922. Gard. Chron., Ser. III 71: 44, 92, 198.

*-1925. Gard. Chron., Ser. III 78: 412, 413, 433.

*-1926. Philips, Gen. S. Afr. Fl. Pl., 249.

*-1926. Brutt Davy, Man. Fl. Pl. and Ferns. pt. 1: 39, 156, 157.

Darlington, C. D. and Wylie, A. P. 1955. Chromosome atlas of flowering plants, George Allen and Unwin Ltd. London.

De Vos, M. P. 1947. Cytological studies in genera of the Mesembryanthemeae. Ann. Univ. Stellenbosch Reeks A 25: 1.

Hagerup, O. 1932. Uber Polyploidy in Beziehung zu Klima, Okologie und Phylogeny. Chromosomzahlen am Timbuktu. Hereditas 16: 19.

Hutchinson, J. 1959. The families of flowering plants, 2: Macmillan \& Co. Ltd. London. Löve, A. and Löve, D. 1949. The geobotanical significance of polyploidy. Portugaliae 
Acta Biol., Series A, Goldschmidt volume: 273.

Raghavan, T. S. and Srinivasan. N. K. 1940. Studies in the Indian Aizoaceae. Ann. Bot. London 4: 651.

Rendle, A. B. 1938. The classification of flowering plants, 2: Cambridge University Press.

*Schwantes 1926. Zeitschr. Sukkulentenk. 2: 175, 176, 179, 181, 186, 189..

*-1927. Zeitschr. Sukkulentenk. 3: 29.

Sharma, A. K. 1956. A new concept of a means of speciation in vegetatively reproducing plants. Caryologia 9: 93-103.

- and Bhattacharyya, N. K. 1956. Cytogenetics of some members of Portulaccaceae and related families. Caryologia 9: 544 .

Snoad, B. 1951. Chromosome number of succulent plants. Heredity 5: 279.

Sugiura, T. 1936. Studies on the chromosome numbers in higher plants with special reference to cytokinesis I. Cytologia 7: 544.

**-1944. Cytologia 13: 352.

* Not consulted in original, vide Index Kewensis.

** Not consulted in original, vide Darlington and Wylie, 1955. 